\title{
$\mathrm{IMS}$ 에서 정책 기반 네트워크 관리 $\mathrm{QoS}$ 적용 모델
}

\author{
한석준 ${ }^{*}$, 이재오 ${ }^{1}$, 강승찬 ${ }^{1}$ \\ ${ }^{1}$ 한국기술교육대학교 전기전자통신공학과
}

\section{A QoS Adaption Model on the Policy-Based Network Management in the IMS}

\author{
Seok-Jun Han ${ }^{1^{*}}$, Jae-Oh Lee $^{1}$ and Seung-Chan Kang ${ }^{1}$ \\ ${ }^{1}$ Department of Electrical, Electronic and Communication Engineering, \\ Korea University of Technology and Education
}

요 약 스마트폰, 태블릿 PC, 넷북 등의 지능형 이동식 단말기 사용자의 급증과 IPTV와 같은 응용 서비스의 발전으 로 멀티미디어 기반 응용 서비스의 수요가 증가하고 있다. 네트워크 자원이 한정되어 있는 상황에서 한정된 자원을 적절하게 조절하기 위한 다양한 정책들이 제안되고 있다. 사용자의 요구에 적합한 멀티미디어 서비스 제공을 위하여 IMS(IP Multimedia Subsystem)가 유무선 통합 제어망으로 각광을 받고 있으며, IMS의 PDF(Policy Decision Function) 를 적용한 정책 기반 모델이 등장하고 있다. 본 논문에서는 IMS의 PDF에서 다양한 프로토콜을 적용한 QoS(Quality of Service) 적용 모델과 이를 이용한 사용자 시나리오를 제안한다.

\begin{abstract}
The need of multimedia based application service is increasing as the number of smart mobile devices such as smart phone, tablet PC, and netbook is increasing rapidly and the development of application service like IPTV. There are various proposed policies to control the limited network resources. The IMS is used to control wired and wireless aggregation network to support multimedia services that are suitable to the user's need and the policy based models using the PDF of the IMS have emerged. In this paper, we propose the QoS adaption model using various protocols with the PDF of the IMS and the user scenario.
\end{abstract}

Key Words : QoS, IMS, PBNM, PDF, SNMP, Diameter, COPS

\section{1. 서론}

최근 스마트 폰, 태블릿 $\mathrm{PC}$, 넷북 등과 같은 모바일 디 바이스가 널리 보급되면서 다양한 종류의 인프라(wifi, wibro, LTE)가 구축되고 있으며, IPTV와 같은 스트리밍 서비스 사용자의 증가로 광대역의 대역폭이 요구되고 있 다. 인터넷이 비즈니스 프로세스, 응용 서비스, 웹 서비스 의 통합을 요구하고 있는 상황에서 IMS를 이용하여 네트 워크를 추상화하고, 클라우드 컴퓨팅을 이용하여 웹기반 서비스들을 통합관리 하는 등에 대한 연구가 활발하다.

네트워크 기반의 서비스 증대로 네트워크 인프라의 확충이 요구되는 상황에서 한정된 자원으로 보다 많은
사용자의 요구를 충족시키기 위한 다양한 QoS 적용 모델 이 제시되고 있다. IMS에서는 정책 설정을 위한 프로토 콜로 Diameter를 권고하지만, Diameter를 지원하지 않는 기존의 장비 및 네트워크를 이용하기 위해서는 Diameter 를 대체할 수 있는 SNMP(Simple Network Management Protocol), COPS(Common Open Policy Server) 등과 같은 정책 설정을 위한 프로토콜을 사용해야 한다. 위의 프로 토콜은 서로 다른 특징을 가지고 있으며, 특징에 따라 성 능 및 정책 설정 시나리오가 달라진다. 따라서 본 논문에 서는 IMS망에서의 다양한 프로토콜을 이용한 정책 기반 네트워크 관리 $\mathrm{QoS}$ 적용 모델을 연구하고 제안한다. 2장 에서 IMS망의 구조와 정책 기반 네트워크 관리에 대해

*Corresponding Author: Seok-Jun Han

Tel: +82-10-3076-6393 email: sjhan@koreatech.ac.kr

접수일 12년 04월 13 일 수정일 12년 05 월 23 일

게재확정일 12 년 07 월 12 일 
설명하고, 3장에서 $\mathrm{IMS}$ 의 $\mathrm{PDF}$ 구조를 설명하고, $\mathrm{QoS}$ 할 당을 위한 PDP(Policy Decision Point)와 PEP(Policy Enforcement Point)사이의 인터페이스와 관련한 프로토콜 에 따른 정책 기반 네트워크 관리 QoS 적용 모델의 시나 리오를 제안하고, 시나리오에 사용한 프로토콜들의 특징 및 성능을 비교 분석한 후, 4장에서 연구에 대한 결론을 제시한다.

\section{2. 관련 연구}

\subsection{IMS(IP Multimedia Subsystem)}

IMS의 주된 목적은 인터넷과 유무선 환경을 통합하여 IP 기반의 멀티미디어 서비스를 제공하는 것이다[1]. IMS 는 개발이 용이하며, 수정하기 쉽다는 장점을 가지고 있 어, 응용 프로그램의 개발자들에게 다양한 네트워크를 고 려하지 않고 개발할 수 있는 환경을 제공한다. IMS는 IETF(Internet Engineering Task Force)의 표준 프로토콜 인 SIP(Session Initiation Protocol)를 이용하여 CSCF(Call Session Control Function) 등을 관리하며, $\mathrm{CSCF}$ 관리 기 능에는 $\mathrm{QoS}$, 과금, 보안 등이 포함된다. 그림 1은 IMS의 구조를 표현한 것이다.

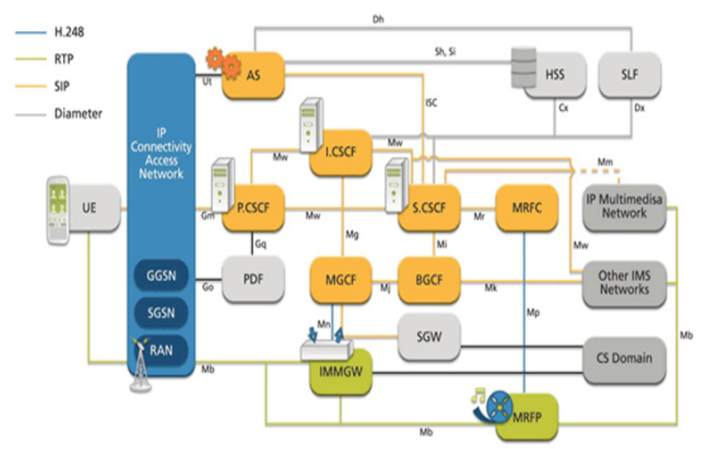

[그림 1] IMS의 구조

[Fig. 1] The Structure of IMS

IMS는 주로 $\mathrm{CSCF}$ 와 HSS(Home Subscriber Server)로 구성되는데, $\mathrm{CSCF}$ 는 기능에 따라 P-CSCF, S-CSCF, $\mathrm{I}-\mathrm{CSCF}$ 로 구분된다. $\mathrm{P}$ (Proxy)-CSCF는 단말이 액세스 망 을 통하여 IMS망에 접속하는 지점으로, 프록시와 사용자 에이전트(UA)의 역할을 수행한다. 사용자의 SIP REGISTER 메시지를 사용자의 홈 도메인을 참조하여 $\mathrm{I}-\mathrm{CSCF}$ 로 전달하고, 사용자의 SIP 메시지를 등록 절차에 따라 S-CSCF로 전달하고, 사용자에게 SIP 메시지를 요구 하거나 응답하는 기능을 수행한다. 또한 $\mathrm{PDF}$ 를 이용하여
$\mathrm{QoS}$ 를 보장할 수 있다[2,3].

I(Interrogating)-CSCF는 사용자의 홈 네트워크 도메인 에 속하는 첫 번째 지점으로써, 하나의 네트워크 도메인 에 다수 존재할 수 있다. 다른 네트워크로부터 수신한 $\mathrm{SIP}$ 메시지를 S-CSCF로 라우팅하고, HSS로부터 $\mathrm{S}-\mathrm{CSCF}$ 의 주소를 얻는 기능을 수행한다.

$\mathrm{S}$ (Serving)-CSCF는 사용자의 인증 및 정보를 $\mathrm{HSS}$ 에 등록하고, 사용자의 최신 가입자 정보를 유지하며, 해당 서비스를 제공하기 위한 서비스 플랫폼과의 상호작용을 통해 사용자에게 서비스 자원과 관련된 정보를 제공한다. $\mathrm{HSS}$ 는 가입자에게 네트워크 접속에 필요한 인증, 권한부 여, 다양한 서비스 정보 제공 등을 수행하는 필수 서버이다.

\subsection{PBNM(Policy Based Network Management)}

정책 기반 네트워크 관리(PBNM)은 IP 기반 네트워크 에서 발생하는 보안이나 $\mathrm{QoS}$ 등의 관리 문제들을 해결하 는데 사용할 수 있는 기술로서, 미리 정의된 정책을 통해 상황에 따라 적절하게 제어가 가능하다는 장점을 가지고 있다[4].

정책 기반 네트워크 관리의 정책은 네트워크 자원을 관리 및 제어하기 위한 규칙의 집합으로, 특정한 상황에 대한 행위의 목적, 순서, 방법 등을 명확히 정의하는 규칙 이다. 핵심이 되는 정책은 지속적인 운용 및 관리를 통해 서 적용 결과를 분석하고, 다시 이를 반영하여 정책을 재 정의 함으로 보다 효율적인 관리를 할 수 있다.

정책 기반 네트워크 관리는 크게 정책을 관리하는 도 구인 PMT(Policy Management Tool), 상황에 따라 적절 한 정책을 결정하는 $\mathrm{PDP}$, 장비의 상태 감시에 따른 정보 를 $\mathrm{PDP}$ 에 전달하고 그에 대한 응답에 해당하는 정책을 수행하는 PEP, 그리고 정책을 저장하는 PR(Policy Repository)로 구성된다.

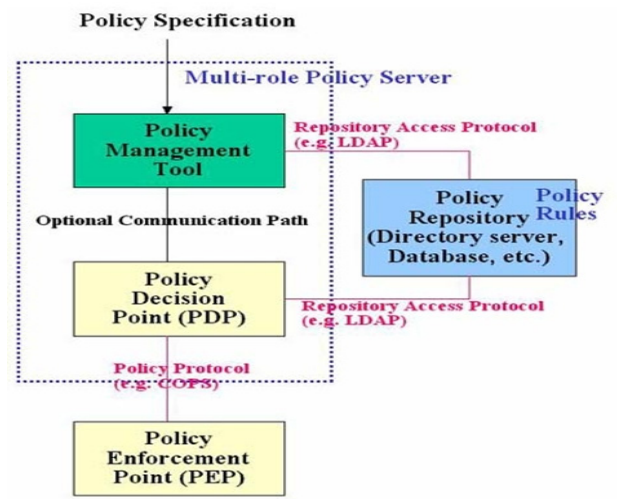

[그림 2] PBNM의 구조

[Fig. 2] The structure of PBNM 
그림 2는 정책 기반 네트워크 관리의 구조를 표현한 것으로 $\mathrm{PDP}$ 와 $\mathrm{PR}$ 사이는 $\mathrm{LDAP}($ Lightweight Directory Access Protocol) 외에 SNMP, CLI 등이 사용될 수 있고, $\mathrm{PDP}$ 와 PEP 사이는 COPS 외에 SNMP, CLI, HTTP, CORBA 등이 사용될 수 있다[5].

\subsubsection{PDP(Policy Decision Point)}

$\mathrm{PDP}$ 는 $\mathrm{PMT}$ 로부터 메시지를 받거나, 네트워크의 상태 변화에 따른 메시지를 받을 때 정책을 설정해야 한다. $\mathrm{PEP}$ 로부터의 보고 또는 요청받은 정보를 통해 장비의 상 태를 분석하고, 분석된 정보로부터 정책 저장소인 PR에 서 적절한 정책을 검색하여 정책을 결정하고, 결정된 정 책을 PEP에 회신하는 역할을 수행한다.

\subsubsection{PEP(Policy Enforcement Point)}

$\mathrm{PEP}$ 는 장비의 구성요소 및 정책 등에 대한 동작 상태 를 감시하고, 동작 상태에 대한 정보를 $\mathrm{PDP}$ 에 전송하고, 전송된 상황에 대한 $\mathrm{PDP}$ 의 정책을 장비가 인식 가능한 명령어 형태로 장비에게 전달하는 역할을 한다. 네트워크 나 장비의 상태가 변화하는 이벤트가 발생하는 경우에 변화된 정보를 PEP에게 보고하는 역할을 한다.

\subsubsection{PR(Policy Repository)}

$\mathrm{PR}$ 은 재사용 가능한 정책요소에 대한 논리적 컨테이 너를 나타낸 추상모델이며, 정책 규칙 및 관련 조건에 대 한 행위, 관련 정책 데이터들에 대한 관리 범위 및 네이 밍을 나타내는 논리적 컨테이너이다. 조건과 행위, 정책 규칙, 관련된 정책 데이터들을 저장하는 정책 저장소로써 데이터베이스 혹은 디렉터리 형태를 갖는다.

\section{3. 정책 기반 QoS 적용 모델}

\subsection{IMS에서의 PDF 구조}

$\mathrm{PDF}$ 는 서비스 기반의 $\mathrm{QoS}$ 정책을 제공하는 시스템으 로 일종의 응용서버처럼 동작한다[6, 7]. P-CSCF의 논리 적인 요소에 해당하는 $\mathrm{AF}$ (Application Function)와 연동 하여 서비스 관련 정보를 제공받고, 해당 정보를 기반으 로 $\mathrm{QoS}$ 정책을 허가하고, $\mathrm{PEP}$ 와 같은 역할을 하는 ACR(Access Control Router), GGSN(Gateway GPRS Support Node) 등의 요청이 있을 때 허가된 QoS 정책을 제공한다. $\mathrm{PDF}$ 는 정책 기반 네트워크 관리에서의 $\mathrm{PDP}$ 컴포넌트와 $\mathrm{PR}$ 의 기능을 함께 수행하는 역할을 한다.

그림 3 은 $\mathrm{PDF}$ 의 구성도를 보여준다. $\mathrm{PDF}$ 는 $\mathrm{PEP}$ 와의
연동을 통하여 해당 정책을 $\mathrm{GGSN}$ 과 $\mathrm{ACR}$ 에 전달하는 기능을 가지며, QoS 정책이 일치하는지를 확인하는 기능 과 사업자의 정책에 따라 그에 상응하는 $\mathrm{QoS}$ 를 적용할 수 있는 정책을 포함하는 권한부여 토큰(Authorization Token)을 생성한다. $3 \mathrm{GPP}$ 에서 제공하는 P-CSCF 구조는 $\mathrm{PDF}$ 기능을 포함할 것을 권고하고 있지만, 필요에 따라 $\mathrm{PDF}$ 는 P-CSCF와 분리될 수 있으며, 분리되어 있을 경우 에는 P-CSCF와 PDF사이의 인터페이스는 Diameter를 이 용한다.

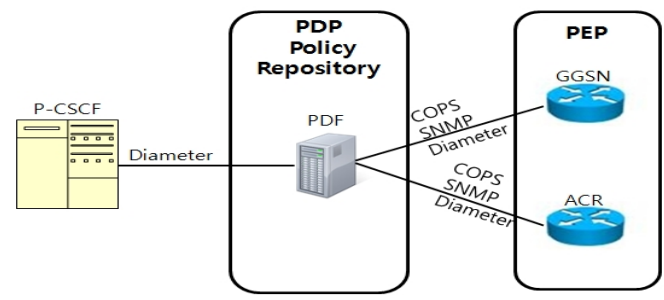

[그림 3] IMS의 PDF 구성도

[Fig. 3] PDF Layout of IMS

그림 4는 P-CSCF와 PDF사이에 Diameter를 이용한 $\mathrm{QoS}$ 요청 과정의 시나리오를 나타낸다.

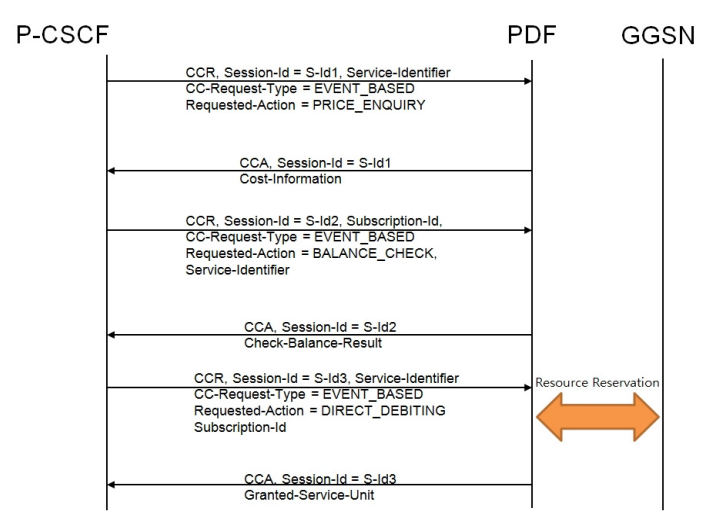

[그림 4] QoS 요청 시나리오

[Fig. 4] The Scenario of QoS request

$3 \mathrm{GPP}$ 정책 기반 구조에서 $\mathrm{PDF}$ 는 $\mathrm{PDP}$ 와 동일하며, $\mathrm{PEP}$ 는 GGSN에 위치한다. $\mathrm{PDF}$ 는 $\mathrm{SDP}$ 와 $\mathrm{HSS}$ 로부터 얻 은 사용자 정보에 기반하여 세션을 허가한다. 세션을 설 립하는 동안 성공적인 SIP 시그널링은 UMTS(Universal Mobile Telecommunications System) 도메인 내의 지역적 인 QoS 예약에 영향을 받고, 이는 PDP Context 시그널링 을 통해 수행된다. PDF에 의해 수행되는 정책승인제어 역시 SIP 시그널링에 영향을 준다. 
$\mathrm{PDF}$ 에 의한 허가는 Go 인터페이스를 이용하여 GGSN 으로 전달된다. $\mathrm{PDF}$ 가 허가를 하면, 권한부여 토큰을 생 성하고 SIP 시그널링을 통해 UE로 전달한다. UE는 이 권한부여 토큰을 PDP Context를 통해 $\mathrm{GGSN}$ 으로 전달하 고, GGSN은 해당 인터페이스를 통해 권한부여 토큰을 전달한다. 이 메시지를 받은 $\mathrm{PDF}$ 는 해당 인터페이스를 이용하여 결과를 $\mathrm{GGSN}$ 에 전달한다. 마지막으로 SIP에 의해 세션이 성립되면, 세션 설립 완료 메시지를 이용해 해당되는 flow가 통과할 수 있도록 한다.

\subsection{PDF와 PEP 사이의 QoS 정책 모델}

IMS가 세션을 제어하는 망을 사용하는 형태이지만, 실제 미디어 전송과 관련한 QoS 정책 설정은 기존의 정 책 설정 과정과 유사한 형태를 가지고 있다. 본 논문에서 는 SNMP, Diameter, COPS 프로토콜을 적용한 $\mathrm{QoS}$ 정책 설정 모델에 따른 시나리오를 다양하게 제시하여 각 프 로토콜에 따른 장점과 단점을 비교할 수 있도록 하였다.

\subsubsection{SNMP 적용 시나리오}

그림 5는 $\mathrm{PDP}$ Agent가 $\mathrm{SNMP}$ 를 사용할 경우 $\mathrm{QoS}$ 정 책 설정 과정을 표현한 것이다.

UE가 INVITE 메시지를 이용하여 P-CSCF에 접속하 면, P-CSCF는 Diameter CCR 메시지를 이용하여 해당 서 비스의 $\mathrm{QoS}$ 할당을 요구하게 되며, $\mathrm{PDF}$ 는 해당하는 $\mathrm{QoS}$ 를 설정하기 위하여 SNMP Set 메시지를 이용하여 GGSN(PEP)에 QoS 할당을 요청한다. QoS 할당 요청 후 요청한 $\mathrm{QoS}$ 의 적용여부를 확인하기 위하여 $\mathrm{PDF}$ 는 SNMP Get 메시지를 이용하여 할당 여부를 확인한다[8].

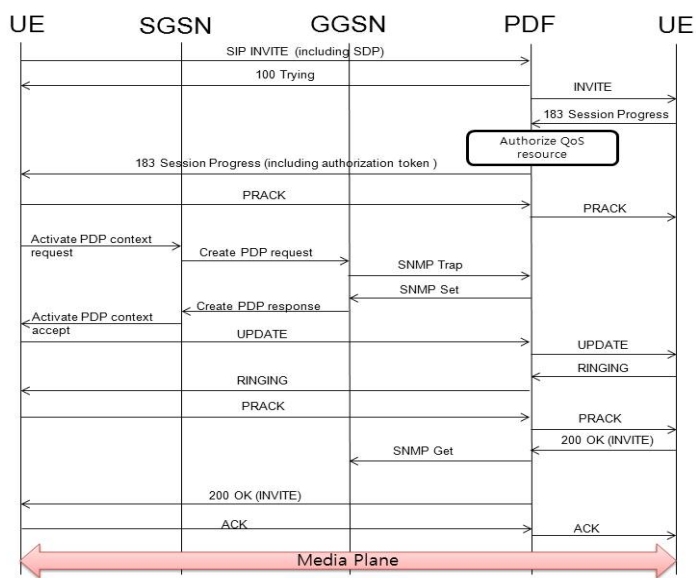

[그림 5] SNMP를 사용한 정책 설정

[Fig. 5] Policy setting using SNMP

\subsubsection{Diameter 적용 시나리오}

그림 6은 PDP Agent가 Diameter를 사용할 경우 QoS 정책 설정 과정을 표현한 것이다.

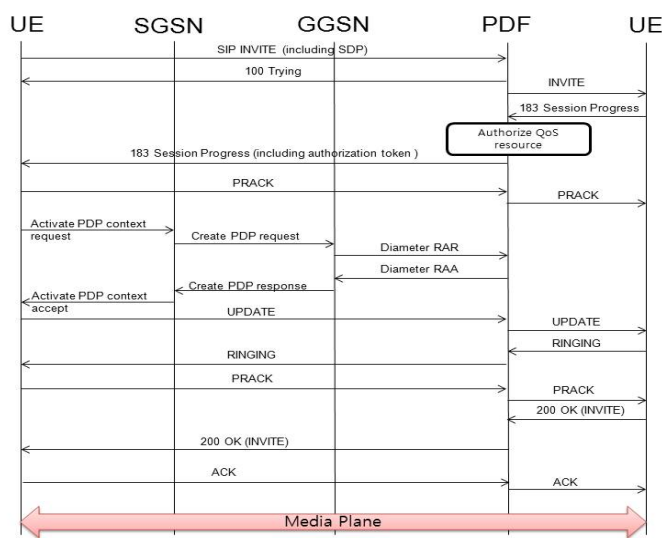

[그림 6] Diameter를 이용한 정책 설정

[Fig. 6] Policy setting using Diameter

$\mathrm{UE}$ 가 PDP Context를 전송하면, Agent를 통하여 QoS 를 설정하기 위하여 RAR 메시지를 이용하여 해당 $\mathrm{QoS}$ 를 GGSN에 설정하며[9], 그 결과는 RAA 메시지를 이용 하여 결과를 $\mathrm{PDF}$ 에 통보한다. RAA 메시지에는 $\mathrm{QoS}$ 할 당 성공 여부에 대한 내용과 관련 정보가 포함되어 있다.

\subsubsection{COPS 적용 시나리오}

그림 7은 $\mathrm{PDP}$ Agent가 $\mathrm{COPS}$ 를 사용할 경우 $\mathrm{QoS}$ 정 책 설정 과정을 표현한 것이다.

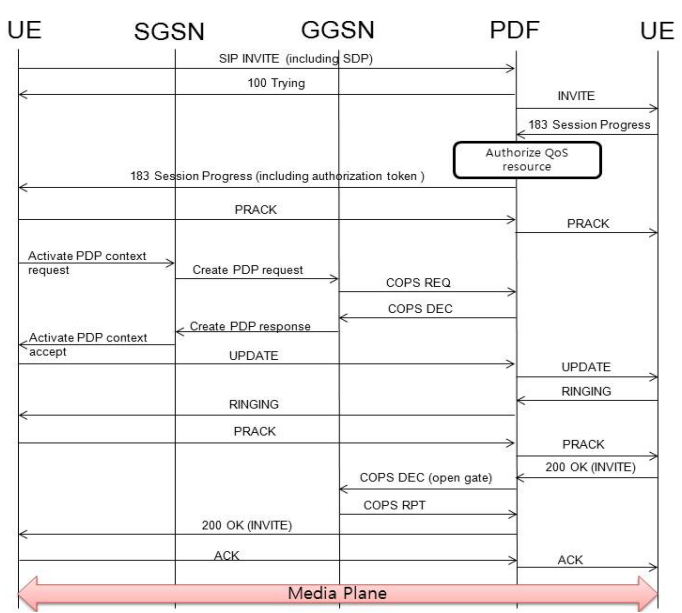

[그림 7] $\mathrm{COPS}$ 를 이용한 정책 설정

[Fig. 7] Policy setting using COPS 
UE로부터 PDP Context가 전송되면, Agent를 통하여 $\mathrm{QoS}$ 를 설정하기 위하여 COPS REQ 메시지를 이용하여 해당 $\mathrm{QoS}$ 를 $\mathrm{GGSN}$ 에 설정하며, 그 결과는 $\mathrm{COPS} \mathrm{DEC}$ 메시지를 이용하여 결과를 PDF에 통보한다. COPS DEC 메시지는 $\mathrm{QoS}$ 할당의 성공여부를 포함하고 있으며, 이 메시지를 받은 PDP Agent는 수행 결과를 COPS RPT 메 시지를 이용하여 PDF에 통보한다.

\section{3 사용자 정책 설정 시나리오}

그림 8은 IMS에서의 응용 서비스(AS) 요청에 따른 정 책 설정 시나리오를 표현한 그림이다.

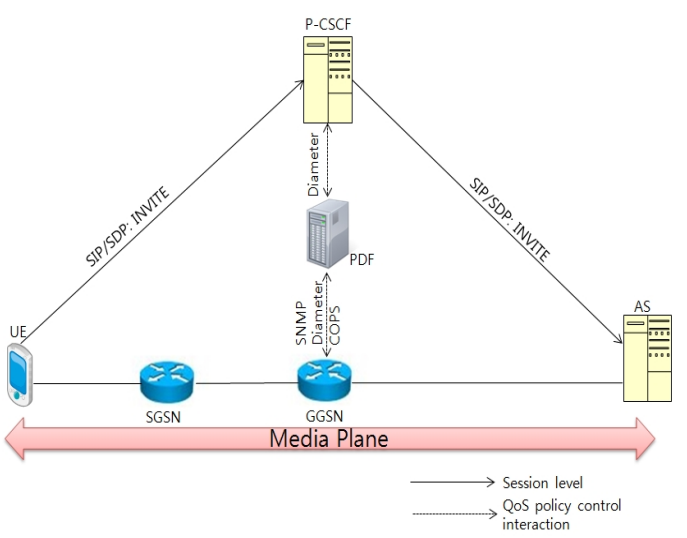

[그림 8] $\mathrm{AS}$ 를 이용한 정책 설정 시나리오

[Fig. 8] Policy setting scenario using AS

사용자가 단말을 이용하여 등록 절차를 마친 후, 응용 서비스(AS)를 이용하려할 때 IMS망의 특성 상 해당 통신 을 위하여 세션 설립과정 및 해당 서비스를 이용하기 위 한 $\mathrm{QoS}$ 를 설정해야 한다. 사용자는 $\mathrm{SDP}$ 를 포함한 $\mathrm{SIP}$ INVITE 메시지를 이용하여 P-CSCF에 접근하고[11], $\mathrm{P}-\mathrm{CSCF}$ 는 PDF를 이용하여 해당 서비스의 정책을 적용 한다. 그리고 적용할 정책을 해당 프로토콜(SNMP, Diameter, COPS)을 이용하여 GGSN에 통보한다.

그림 9는 단말이 해당 응용 서버에 접근하기 위하여 사용하는 SIP INVITE 메시지에 포함되는 SDP 정보를 나타내며, "i" 파라미터는 INVITE 메시지의 미디어의 타 입 정보를 포함하며, " $m$ " 파라미터는 미디어 라인의 타 입(audio or video session) 정보를 포함하고 있다. 또한 $\mathrm{SDP}$ 의 "b" 파라미터 값을 이용하여 해당서비스의 대역 폭을 설정할 수도 있다. $\mathrm{v}=0$

$0=$ ecsreid 3262464865 3262464868 IN IP6 2001:0646:00F1:0045:02D0:59FF:FE14:F33A $\mathrm{s}=\mathrm{MM} 01$

$i=0$ ne unidirectional audio media and one unidirectional video media and one bidirectional application media

$t=32623776003262809600$

$\mathrm{m}=$ video 50230 RTP/AVP 31

c=IN IP6 2001:0646:00F1:0045:02D0:59FF:FE14:F33A

a=recvonly

$\mathrm{m}=$ audio 50330 RTP/AVP 0

c=IN IP6 2001:0646:00F1:0045:02D0:59FF:FE14:F33A

a=sendonly

$m=$ application 50430 udp wb

$c=I N$ IP6 2001:0646:00F1:0045:02D0:59FF:FE14:F33A

$\mathrm{a}=$ sendrecv

[그림 9] UE가 전송한 $\mathrm{SDP}$ 메시지

[Fig. 9] SDP Message received from UE

그림 10은 P-CSCF로부터 AS에 전송되는 SIP INVITE 메시지에 포함되는 SDP 정보를 나타내며, SDP 파라미터 값을 이용하여 PDF는 표 1과 같은 Flow identifier의 리스 트를 생성한다.

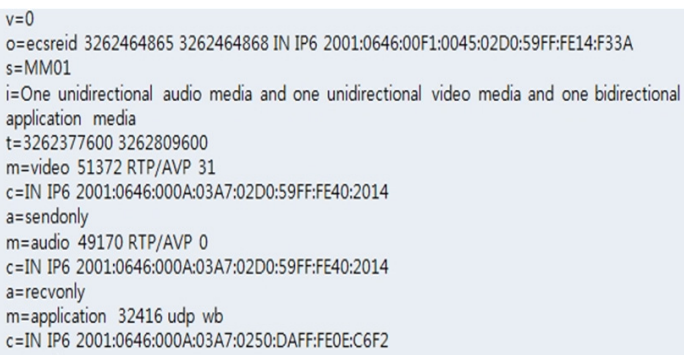

[그림 10] $\mathrm{AS}$ 에 전달된 $\mathrm{SDP}$ 메시지

[Fig. 10] SDP Message delivered to AS

[표 1] PDF가 생성한 Flow identifier 리스트

[Table 1] Flow identifier list made by PDF

\begin{tabular}{|c|c|c|c|}
\hline $\begin{array}{l}\text { Order of } \\
\text { 'm='-line }\end{array}$ & Type of IP flows & $\begin{array}{c}\text { Destination IP Address / } \\
\text { Port number of the IP flows }\end{array}$ & $\begin{array}{c}\text { Flow } \\
\text { identifier }\end{array}$ \\
\hline 1 & RTP (Video) DL & 2001:0646:00F1:0045:02D0.59FF:FE14:F33A / 50230 & $<1,1>$ \\
\hline 1 & RTCP DL & 2001:0646:00F1:0045:02D0:59FF:FE14:F33A / 50231 & $<1,2>$ \\
\hline 1 & RTCP UL & 2001:0646:000A:03A7:02D0.59FF:FE40:2014 / 51373 & $<1,2>$ \\
\hline 2 & RTP (Audio) UL & 2001:0646:000A:03A7:02D0.59FF:FE40:2014 / 49170 & $<2,1>$ \\
\hline 2 & RTCP DL & 2001:0646:00F1:0045:02D0:59FF:FE14:F33A / 50331 & $<2,2>$ \\
\hline 2 & RTCP UL & 2001:0646:000A:03A7:02D0.59FF:FE40:2014 / 49171 & $<2,2>$ \\
\hline 3 & $\begin{array}{c}\text { UDP } \\
\text { (application) DL }\end{array}$ & 2001:0646:00F1:0045:02D0:59FF:FE14:F33A / 50430 & $<3,1>$ \\
\hline 3 & \begin{tabular}{|c|} 
UDP \\
(application) UL
\end{tabular} & 2001:0646:000A:03A7:0250:DAFFFEOE:C6F2 / 32416 & $<3,1>$ \\
\hline
\end{tabular}

$\mathrm{SDP}$ 의 "m" 파라미터 값을 이용하여 해당 메시지가 사 용하는 미디어 타입 및 응용 서비스 타입을 판단하며, 이 를 이용하여 Flow identifier를 생성한다. Flow identifier 는 2 개의 튜플(tuple)로 구성되는데, 첫 번째 숫자는 SDP 
의 "m" 파라미터 값을 이용하여 생성한 숫자이며, 두 번 째 숫자는 Flow의 순서를 의미한다.

\section{4 프로토콜 비교 및 성능 분석}

표 2는 본 논문에서 정책설정을 위해 사용한 프로토콜 들을 비교 분석한 내용을 요약한 것으로, 표의 숫자는 각 프로토콜 사이를 비교한 수치로 적을수록 성능이 우수함 을 나타낸다[10].

[표 2] 각 프로토콜의 성능 비교 분석

[Table 2] The Performance Analysis of Each Protocol

\begin{tabular}{|c|c|c|c|c|c|}
\hline & 지연 & 메모리 & 오버헤드 & 확장성 & 패킷 수 \\
\hline SNMP & 2 & 3 & 3 & 3 & 3 \\
\hline Diameter & 3 & 2 & 2 & 2 & 2 \\
\hline COPS & 1 & 1 & 1 & 1 & 1 \\
\hline
\end{tabular}

$\mathrm{SNMP}$ 는 다른 프로토콜에 비해 성능이 뒤떨어지는 특 성을 가지고 있지만, 현재까지 가장 많이 사용된 프로토 콜로 구현이 용이하고 오류에 대한 피드백이 빠르다는 장점을 가지고 있다. 반면에 정책 설정을 위해서는 $\mathrm{QoS}$ 할당 여부를 확인하기 위한 메시지를 추가적으로 사용해 야 한다는 단점을 가지고 있다. 확장성이 떨어지는 단점 때문에 주로 모니터링에 국한되어 사용된다.

Diameter는 COPS와 SNMP의 중간 정도에 해당하는 성능을 가지고 있으며, 비교 대상의 프로토콜에 비해 지 연이 많이 발생하는 단점을 가지고 있다. AAA와 이동성 관리를 위한 시그널링 프로토콜로 초기에 채택되었지만, IMS의 $\mathrm{Cx}, \mathrm{Dx}, \mathrm{Go}, \mathrm{Ro}, \mathrm{Sh}$ 등의 인터페이스와 non-IMS 의 서비스에 따라 다양한 메시지를 교환할 수 있다는 장 점을 가지고 있어, 다양한 형태의 서비스를 제공하는데 사용될 수 있는 커다란 장점을 가지고 있다.

COPS는 세 개의 비교 프로토콜 중 가장 성능이 우수 하고, 매우 효율적인 프로토콜로 평가가 되는 프로토콜로 서, IMS에서 PDF와 GGSN 엔티티의 Go 인터페이스에 사용되는 프로토콜로 $\mathrm{QoS}$ 와 과금과 관련된 정보의 전송 에 사용된다. COPS 프로토콜을 지원하는 네트워크 장비 는 $\mathrm{PEP}$ 의 역할을 수행하므로 정책 설정 값의 일관성을 유지할 수 있지만, 장비가 COPS를 지원하지 못하는 경우 $\mathrm{PEP}$ 를 별도의 소프트웨어로 운용하는 상황이 발생하고, $\mathrm{PEP}$ 와 장비 사이에 별도의 프로토콜을 이용하여 정책 설 정 값이 전달되는 상황에서, 정책 설정 값에 대한 일관성 문제가 야기될 수 있다는 단점을 가지고 있다.

표 3은 본 논문의 정책 설정 시나리오에 사용된 프로 토콜에 따른 INVITE와 정책설정을 위한 트랜잭션의 개
수를 비교한 자료이다.

[표 3] 트랜잭션의 개수 비교 분석

[Table 3] The Analysis of the Number of Transaction

\begin{tabular}{|c|c|c|}
\hline & $\begin{array}{c}\text { INVITE } \\
\text { 트랜잭션 수 }\end{array}$ & $\begin{array}{c}\text { 정책 설정을 위한 } \\
\text { 트랜잭션 수 }\end{array}$ \\
\hline SNMP & 3 & $1 \sim 2$ \\
\hline Diameter & 3 & 1 \\
\hline COPS & 3 & 2 \\
\hline
\end{tabular}

사용자 등록 과정이 완료된 후, 정책 설정을 위하여 사 용된 INVITE 트랜잭션의 수는 동일하지만, 정책 설정을 위한 트랜잭션의 수는 정책설정 과정의 차이로 트랜잭션 의 수가 서로 다르다.

$\mathrm{SNMP}$ 는 정책 설정을 위한 트랜잭션은 1 개만 사용되 었으며, 추가적으로 설정된 정책의 설정 여부를 확인하기 위하여 경우에 따라 하나의 트랜잭션을 추가하여 $(\mathrm{Get})$ 확 인할 수 있었다. Diameter는 정책설정을 위한 트랜잭션은 1 개만 사용하였으며, RAA 메시지에 정책 설정의 결과 여부가 포함되어 있으므로 추가적인 트랜잭션은 필요하 지 않았다. COPS는 2개의 트랜잭션을 이용하였으며, 설 정을 위한 1 개의 트랜잭션 이외에도 설정 결과의 리포트 를 받아보기 위한 메시지를 위한 1 개의 트랜잭션 $(\mathrm{DEC} / \mathrm{RPT})$ 을 추가적으로 사용하였다.

\section{4. 결론}

스마트폰, IPTV, M2M(Machine to Machine) 등과 같 은 통신을 이용하는 사용자의 증가로 한정된 네트워크 자원을 효율적으로 관리해야 하는 필요성이 제시되고 있 는 상황에서 네트워크 자원 관리를 위한 정책 설정은 매 우 중요하다.

본 논문에서는 유무선 통합망인 IMS망에서의 SNMP, Diameter, COPS를 이용한 정책 기반 $\mathrm{QoS}$ 적용 모델에 따른 정책 설정 과정에 대한 시나리오를 제안하고, 정책 설정과 관련한 각 프로토콜의 장점과 단점을 비교 분석 하였다. 연구 결과는 네트워크 관리 $\mathrm{QoS}$ 정책 설정에 따 른 프로토콜의 선택과 시나리오를 적용하는데 활용될 수 있다.

제안된 QoS 정책 설정 모델에 대한 시나리오를 활용 한 구현 및 성능평가를 통해 상황에 따른 최적의 모델을 제시하는 향후 연구가 필요하다. 


\section{References}

[1] 3GPP TS 23.228, "IP Multimedia Subsystem (IMS); Stage 2", V10.0.0, March 2010.

[2] 3GPP TS 29.207, “ Policy control over Go interface R7”, June 2007.

[3] 3GPP TS 29.212, " Policy and Charging Control over Gx reference point”, September 2007.

[4] 3GPP TR 23.802, "Architectural enhancements for end-to-end Quality of Service(QoS) R7”, June 2007.

[5] Vallejo, Zaballos, Campos, Dalmau, "Optimizing the Usage of COPS Protocol in ITU-T NGN Architecture" AICT, May 2010.

[6] Nae-Son Lee, Jae-Oh Lee, "Police Based Network Management in the IMS", KNOM Review, Vol. 10, No.1, August 2007.

[7] Bo Yu, Dong Yu, Junying Jia, JinghuaLin, "A Review of the Policy-Based QoS Architecture in IMS", PCSPA 2010 pp. 189-192, September 2010.

[8] Gil Heo, Eunhoe Kim, Jaeyoung Choi, "An Extended SNMP-based Management of Digital Convergence Devices", Computer and Information Technology, June 2010.

[9] P. Calhoun, J. Loughney, E. Guttman, G. Zorn, J. Arkko, "Diameter Base Protocol", RFC 3588, September 2003.

[10] Pedro Gonçalves, José Luís Oliveira, and Rui L. Aguiar,"An evaluation of network management protocols",Integrated Network Management, 2009.

[11] J. Rosenberg et al., "SIP: Session Initiation Protocol.", IETF RFC 3261, June 2002.

\section{한 석 준(Seok-Jun Han)}

[정회원]

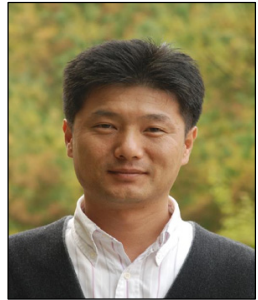

- 1996년 2월 : 한국기술교육대학 교 정보통신공학과 졸업(공학사)

- 1999년 2월 : 고려대학교 전기전 자전파공학부 졸업(공학석사)

- 2005년 3월 현재 : 한국기술 교육대학교 전기전자통신공학과 (박사과정)

<관심분야>

IMS, QoS, 네트워크 관리, 인터네트워킹

\section{이 재 오(Jae-Oh Lee)}

[정회원]

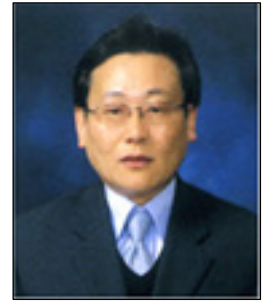

- 1993년 2월 : 광운대학교 전산학 과 졸업(공학박사)

- 1994년 3월 1995년 2월 : 코 오롱 정보통신 연구소 과장

- 1995년 2월 2000년 12월 : $\mathrm{KT}$ 선임연구원

- 1999년 9월 2002년 8월: (주) 웨어플러스 연구소장

- 2002년 8월 현재 : 한국기술교육대학교 전기전자통 신공학과 교수

<관심분야>

네트워크 관리 및 IMS, 객체 지향 분산 처리기술, $\mathrm{QoS}$ 제어플랫폼, 개인화서비스, $\mathrm{M} 2 \mathrm{M}$

\section{강 승 찬(Seung-Chan Kang)}

[정회원]

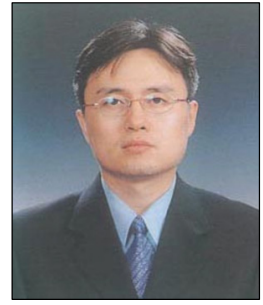

- 1986년 2월 : 한양대학교 전자공 학과 졸업(공학사)

- 1988년 2월 : 한양대학교 전자공 학과 졸업(공학석사)

- 1993년 2월 : 한양대학교 전자공 학과 졸업(공학박사)

- 1993년 3월 현재 : 한국기술 교육대학교 전기전자통신공학과 교수

<관심분야>

네트워크 관리, QoS, 인터네트워킹, 멀티캐스트, 원격교 육, 공학인증, e-learning 